\title{
Pneumoperitônio idiopático: relato de caso
}

\section{Idiopathic pneumoperitoneum: case report}

\author{
Enio Campos Amico"; Danilo Vendrame Vivas²; José Roberto Alves, ACBC-SC3
}

\section{INTRODUÇÃO}

O pneumoperitônio é causado freqüentemente por perfurações de vísceras ocas, entretanto, em aproximadamente $10 \%$ dos casos pode estar presente na ausência dessas' ${ }^{1}$. Quando nenhuma causa é encontrada, é definido como idiopático. É considerado uma condição rara, pois nos últimos 30 anos, pouco mais de 20 casos foram descritos ${ }^{2}$.

Assim, pretendemos relatar mais um caso de pneumoperitônio idiopático, como também, oferecer suporte teórico-prático na investigação etiológica de casos de pneumoperitônio na prática médica.

\section{RELATO DO CASO}

Um paciente com 45 anos, branco, procurou o Pronto Socorro do Hospital Municipal Regional Campo Limpo com dor abdominal há aproximadamente 24 horas, tipo pontada, inicialmente infra-umbilical de pequena intensidade que depois progressivamente tornou-se intensa passando a irradiar-se para tórax e para o ombro direito, sem outros comemorativos. Ao exame físico estava em bom estado geral com alteração apenas do pulso (120 bpm) e do abdome que se apresentava doloroso difusamente à palpação profunda, com sinal de Jobert presente, porém sem sinais de irritação peritoneal. Negava história pregressa de outras doenças, laparotomia, tabagismo, uso de medicações e drogas ilícitas. Referia ingesta alcoólica ( $\mathrm{H}^{\prime \prime} 20 \mathrm{~g}$ de álcool etílico/dia).

Dos exames complementares solicitados, apenas o leucograma estava alterado (leucocitose de 17.580 $\mathrm{p} / \mathrm{mm}^{3}$, sem desvio à esquerda) e as radiografias que evidenciavam um pneumoperitônio de grandes proporções (Figuras 1 e 2). Em virtude do quadro, indicou-se a laparotomia exploradora. Na abertura da cavidade (incisão mediana), identificou-se saída de ar, logo após incisão do peritônio. No inventário da mesma foi procedida a inspeção e palpação de todos os órgãos parenquimatosos, diafragma, estômago (após acesso a retro-cavidade dos epíplons), do duodeno (após manobra de Kocher), do in- testino delgado e grosso (após descolamento de ambas as goteiras parietocólicas). Nenhuma alteração foi encontrada. Por fim, através da sonda nasogástrica, foi insuflado ar no estômago evidenciando ausência de escape aéreo.

O paciente evoluiu com melhora da dor abdominal e sem complicações pós-operatórias. O período de internação se prolongou por cinco dias para que se pudesse realizar melhor investigação com relação à possível etiologia do pneumoperitônio, através de exames complementares de imagem e endoscópicos. O paciente foi

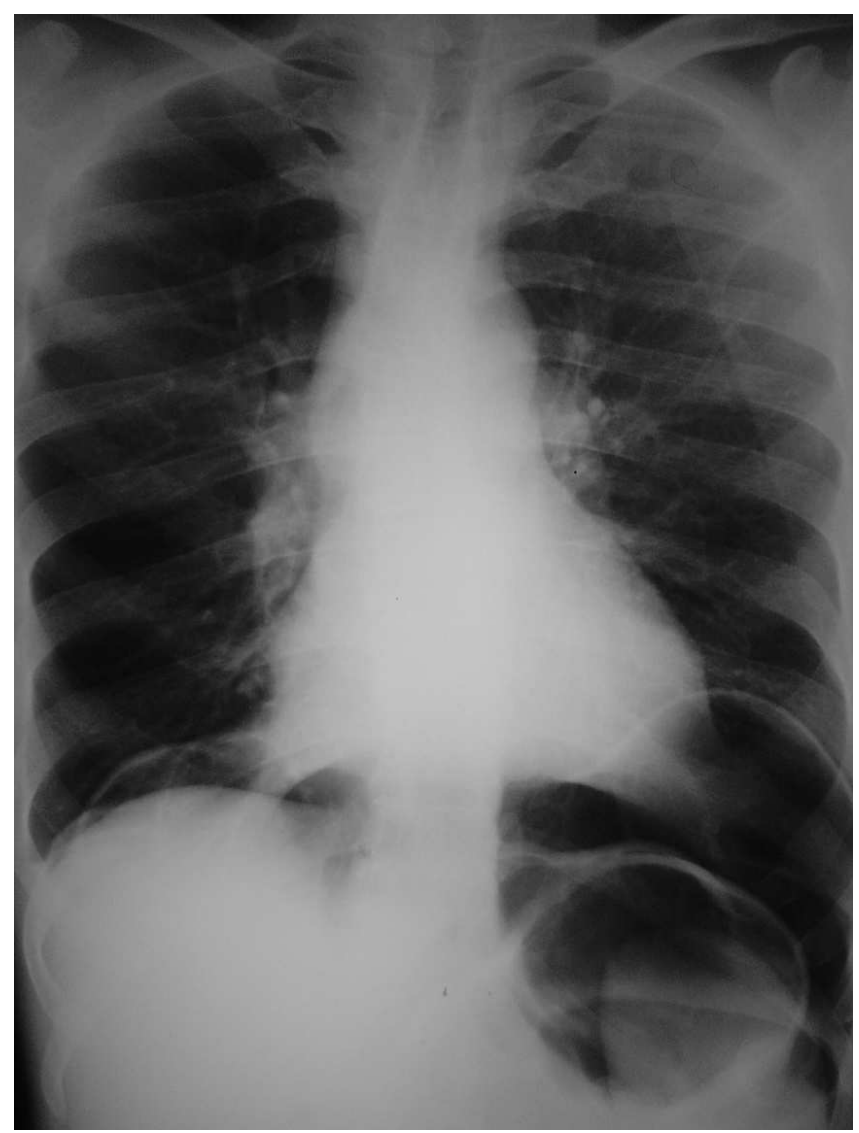

Figura 1 - Radiografia de tórax, ortostática, demonstrando presença de ar infradiafragmático (pneumoperitônio bilateral).

Trabalho realizado no Hospital Municipal Regional Campo Limpo - SP.

1. Mestre e Doutor pela Faculdade de Medicina da Universidade de São Paulo e Cirurgião do Hospital Municipal Regional Campo Limpo - SP; 2. Médico Residente de Cirurgia Geral do Hospital Municipal Regional Campo Limpo - SP; 3. Médico Cirurgião do Departamento de Emergência do Hospital Universitário Polydoro Ernani São Thiago da UFSC-SC- BR. 


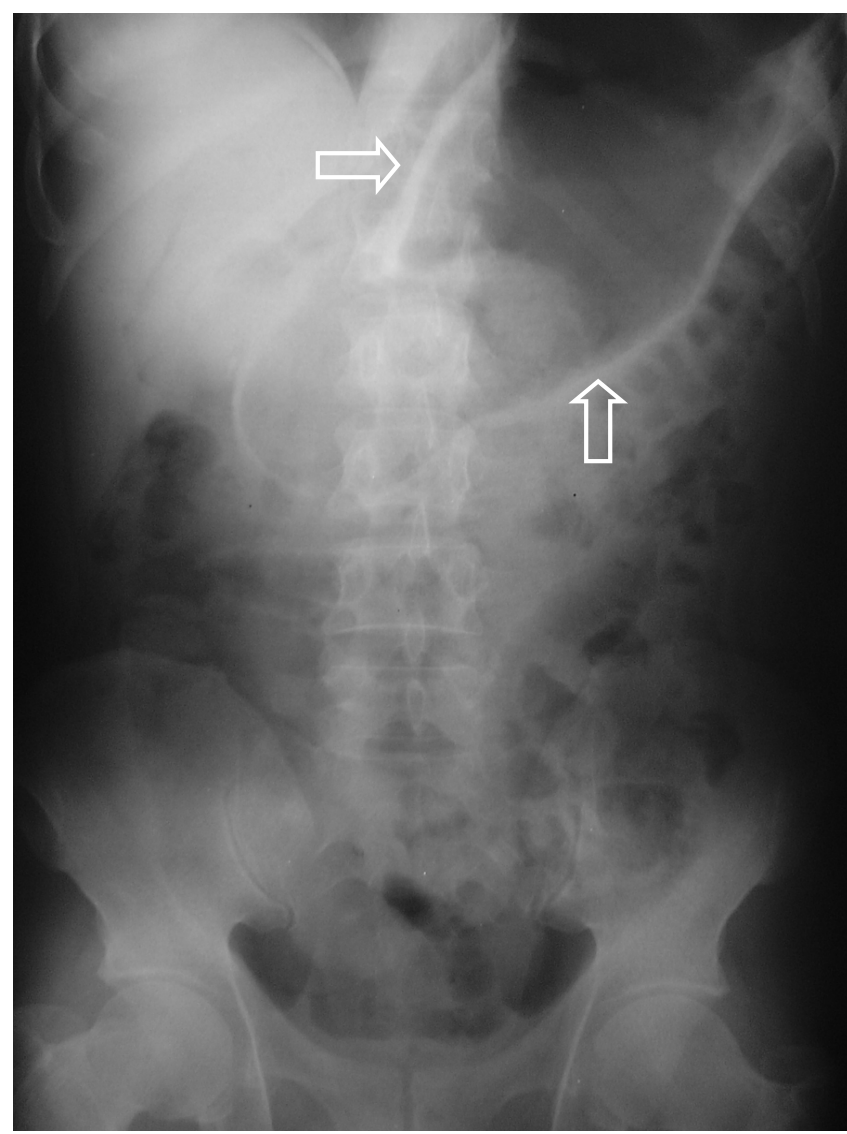

Figura 2 - Radiografia de tórax, ortostática, demonstrando o Sinal de Rigler. As setas apontam para a parede gástrica realçada pela presença de ar dentro e fora do órgão.

submetido à tomografia de tórax e colonoscopia que não evidenciaram alterações, esta realizada no último dia de internação com intuito de minimizar possíveis riscos de complicações inerentes a sua realização. Além disso, foi submetido à endoscopia digestiva alta que evidenciou apenas uma úlcera gástrica rasa com $7 \mathrm{~mm}$, coberta por fibrina.

\section{DISCUSSÃO}

O pneumoperitônio pode ser causado por condições cirúrgicas e não cirúrgicas (abdominais, torácicas e ginecológicas) ${ }^{2}$. No maior estudo uni-institucional publicado sobre o tema, nove pacientes foram estudados no período de nove anos; em $66,6 \%$ dos casos a origem do pneumoperitônio foi abdominal: pneumatose cística intestinal, abscesso hepático, microtraumas da transição esofagogástrica por vômitos, trauma da parede gástrica após hiperinsuflação gástrica durante ressuscitação cardiopulmonar e colite ${ }^{3}$.

Os achados intra-operatórios e de exames complementares realizados durante a investigação não encontraram causa torácica e abdominal para o pneumoperitônio. Deve-se destacar que não ocorreu durante o atendimento do paciente necessidade de ressuscitação cardiorrespiratória. Quanto às causas abdominais de pneumoperitônio não-cirúrgico, não havia história de procedimentos endoscópicos, enemas ou punções percutâneas, assim como durante a exploração cirúrgica não evidenciou presença de cistos em parede do cólon.

Pouco mais de 20 casos de pneumoperitônio sem causa comprovada foram descritos na literatura, no entanto, na maioria dos casos algumas suspeitas puderam ser feitas em virtude de condições clínicas associadas ao aparecimento do pneumoperitônio: pseudo-obstrução do cólon, uso de cocaína (crack), efeito de radioterapia, entre outras ${ }^{2,4}$. No presente caso, após completa investigação, concluímos que o pneumoperitônio de fato, é idiopático.

O volume de ar presente na cavidade abdominal chamou atenção por sua magnitude, pela presença do Sinal de Rigler, visualizado na radiografia de abdome somente quando aproximadamente um litro de ar está presente na cavidade abdominal ${ }^{5}$. Assim, podemos considerar o atual caso como um pneumoperitônio idiopático de volume considerável.

Por fim, é válido ressaltar que frente a um caso de pneumoperitônio ainda devemos manter a clássica conduta, após sua identificação radiológica, de tratamento cirúrgico, independente de sua etiologia, sem gerar para isto maior morbimortalidade ao nosso paciente, visto que os riscos inerentes à laparotomia exploradora não suplantam os riscos de se deixar uma possível causa de pneumoperitônio sem tratamento, não justificando retardálo em busca de uma causa em pacientes que esteja em condições semelhantes ao nosso.

\section{A $B$ S S T $R$ R A C T}

Idiopathic pneumoperitoneum is considered a rare condition, as only twenty cases have been described in the last thirty years. The authors report a case of idiopathic massive pneumoperitoneum in a patient aged 45, showing the possible causes of this clinical picture based on a review of medical literature.

Key words: Pneumoperitoneum. Pneumoperitoneum/etiology. Diagnosis. 


\section{REFERENCIAS}

1. Guillem P. Radiologic pneumoperitoneum without perforation of a hollow viscus. J Chir 2002; 139(1):5-15.

2. Mularski RA, Sippel JM, Osborne ML. Pneumoperitoneum: a review of nonsurgical causes. Crit Care Med 2000; 28(7):2638-44.

3. Korbicka J, Capov I, Vlcek P. Pneumoperitoneum without perforation of the digestive tract. Rozhl Chir 2002; 81(7):364-71.

4. Chan YC, Camprodon RA, Kane PA, Scott-Coombes DM. Abdominal complications from crack cocaine. Ann R Coll Surg Engl 2004; 86(1):47-50.

5. Levine MS, Scheiner JD, Rubesin SE, Laufer I, Herlinger H. Diagnosis of pneumoperitoneum on supine abdominal radiographs. AJR Am J Roentgenol 1991; 156(4):731-5.
Recebido em 07/02/2007

Aceito para publicação em 09/03/2007

Conflito de interesse: nenhum

Fonte de financiamento: nenhuma

\section{Como citar este artigo:}

Amico EC, Vivas DV, Alves JR. Pneumoperitônio idiopático: relato de caso e revisão de literatura. Rev Col Bras Cir. [periódico na Internet] 2011; 38(2). Disponível em URL: http://www.scielo.br/rcbc

Endereço para correspondência:

José Roberto Alves

E-mail: jrobertoa@uol.com.br 